\title{
Significance of geographical factors (climatic, topographic and social) to the COVID-19 outbreak in India
}

\author{
Amitesh Gupta ${ }^{\mathrm{a}, \mathrm{b} 1} \bullet$ Sreejita Banerjee ${ }^{\mathrm{c}} \cdot$ Sumit Das $^{\mathrm{c}}$ \\ ${ }^{a}$ Marine and Atmospheric Sciences Department, Indian Institute of Remote Sensing (ISRO), Dehradun, \\ India \\ ${ }^{b}$ Department of Remote Sensing and GIS, JIS University, Kolkata, India \\ ${ }^{c}$ Department of Geography, Savitribai Phule Pune University, Pune 411007, India
}

\begin{abstract}
:
Very recently, large outbreak of COVID-19 cases all around the world has also whacked India since approximately 30,000 cases confirmed within first three months of transmission. The present study used long-term climatic records of air temperature $(T)$, rainfall $(\mathrm{R})$, actual evapotranspiration (AET), solar radiation (SR), specific humidity ( $\mathrm{SH}$ ), wind speed (WS) with topographic altitude (E) and population density (PD) at regional level to investigate the spatial association with number of COVID-19 infections (NI). Bivariate analysis failed to find any significant relation (except SR) with the number of infected cases within 36 provinces in India. Variable Importance of Projection (VIP) through Partial Least Square (PLS) technique signified higher importance of SR, T, R and AET. However, Generalized Additive Model (GAM) fitted with log-transformed value of input variables and applying spline smoothening to PD and E, significantly found high accuracy of prediction $\left(\mathrm{R}^{2}=0.89\right)$, thus, well explained the complex heterogeneity among association of regional parameters with COVID-19 cases in India. Our study suggests that comparatively hot and dry regions in lower altitude of the Indian territory are more prone to the infection by COVID-19 transmission.
\end{abstract}

Keywords: COVID-19, Geographical factors, Climatic influence, Generalized Additive Model, India

\section{Introduction:}

Coronavirus disease 2019 (Covid-19) already considered as a global pandemic, is rapidly spreading across the world and significantly affecting many countries (Singhal 2020; Asyary and Veruswati 2020). This outbreak of a novel coronavirus (SARS-CoV-2) disease began in December 2019 in Wuhan, Hubei Province, China (Gorbalenya 2020; Ma et al. 2020; Wu et al. 2020). By March 25, 2020, the disease had rapidly spread from Wuhan to 196 countries, located in different parts of the world (Chen et al. 2020; Xu et al. 2020). As

\footnotetext{
${ }^{1}$ Email:amitesh13gupta14@gmail.com (Amitesh Gupta)
}

of April 28, 2020, there have been a total of 3.12 million confirmed cases from all around the world. This contact transmissible disease has an average incubation period from 6-14 days (Tosepu et al 2020). Fever, respiratory disorder, coughing and shortness of breath are some of the early symptoms while in acute stage it can lead to death (Holshue et al. 2020; Perman 2020; Tosepu et al 2020).

According to $\mathrm{WHO}$, the first infected case in India was reported on Jan 30, 2020. Later, around March 4 onwards, it turned into a major outbreak. Till April 27, 
Maharashtra is the leading state with a total number of 8,590 cases, while the whole country recorded a total of 29,458 cases. Social distancing is the only measure that is adopted due to lack of vaccine. SARS-CoV2 can be transmitted through various bioaerosols, large droplets or direct contact with secretions similar to the influenza virus (Li et al., 2005; Qi et al. 2020). Virus transmission can be influenced by several geographical factors such as climatic conditions (temperature and humidity) and population density (Dalziel et al., 2018; Casanova et al. 2010). It was observed that the outbreak is more severe in the countries located in the mid-latitude where the temperature is considerably low in contrast to the tropical countries. Many researchers from different parts of the world tried to establish a relationship between COVID-19 transmission and various meteorological factors (Bashir et al. 2020; Patra et al. 2020; Shi et al. 2020). In a study conducted in New York, USA, using Kendall and Spearman rank correlation test it was found that mean temperature, minimum temperature and air quality has a significant association with the COVID-19 pandemic (Bashir 2020). Shi et al. (2020) reported a significant correlation between daily temperature and daily count of COVID-19 cases in China, and suggested that temperature above 8 to $10{ }^{\circ} \mathrm{C}$ would lead to the declination of infected cases. Patra et al. (2020) concluded that a rise in $1{ }^{\circ} \mathrm{C}$ temperature would result to a decrease in the number of daily confirmed COVID19 cases in Brazil.

In India, so far no comprehensive study regarding the climatic influences on Covid19 has been reported. Therefore, in this study, we investigated the correlations among climatic and topographic factors with state-wise total number of infected cases. The main goal is to examine scientific evidence about the spread of COVID-19 cases in India based on regional factors, including population density, climatic conditions and topography.

\section{Data and methodology:}

\subsection{Data collection:}

In this study, we made an attempt to correlate different climatic and topographic variables with the number of Covid-19 infections in different states of India. We retrieved data regarding the number of Covid-19 cases in all the states of India as of April 27 $7^{\text {th }}, \quad 2020$ from https://www.covid19india.org/. Population density data were acquired from census India website (https://www.census2011.co.in). Due to limitation of the daily ground-monitored weather data in India, we obtained longterm annual climatic data (viz. temperature, rainfall, actual evapotranspiration, wind speed, solar radiation, and specific humidity) from TerraClimate and Worldclim websites (http://www.climatologylab.org/terraclima te.html). Shuttle Radar Topographic Mission (SRTM) digital elevation model of $90 \mathrm{~m}$ spatial resolution were obtained from CGIAR website (http://srtm.csi.cgiar.org/).

\subsection{Determination of climatic zones:}

The first part of our research was intended to understand the relative climatic conditions of different states. Hence, we implemented De Martone aridity-humidity index (De Martonne 1925). Although, this methodology is more appropriate in a small area (Baltas 2007). However, due to its easier calculation and fair generalization, the approach was implemented for regional classification (Ahmadi et al. 2020). Moreover, due to the easier availability of temperature and rainfall data this method has wider popularity (Zareiee 2014). The computation of the aridity index was done by the following equation:

$$
I_{D M}=\frac{P}{T+10}
$$

where $\mathrm{I}_{\mathrm{DM}}$ denotes the aridity index, $\mathrm{P}$ is the annual mean precipitation in $\mathrm{mm}$, and $\mathrm{T}$ is the annual mean air temperature in $\mathrm{flC}$. 


\subsection{Correlation and bivariate linear regression:}

At first, we implemented Pearson product moment correlation to the number of infected cases with all input variables to find out their inter-correlations. Then, bivariate linear regression was done in order to determine if there were any existence of significance between the topo-climatic factors with the COVID-19 transmissions.

\subsection{Variable importance of projection:}

Partial least square regression (PLS) is a common method that reduces the predictor variables to a smaller set of uncorrelated components and then it instead of original data, it runs least square regression on the reduced number of components. In general, PLS is very useful in collinear predictor variables. However, PLS is having a component called Variable Importance of Projection (VIP) that determines the relative importance of each factor (Akarachantachote et al. 2014). For easier computation of relative importance, we applied PLS in our topo-climatic data to construct a model and determine the relative importance of the variables. The VIP score of variable $(\mathrm{j})$ can be calculated using the following equation:

$$
V I P_{j}=\sqrt{\frac{\sum_{a=1}^{h} R^{2}\left(y, t_{a}\right)\left(\frac{W_{a j}}{\left\|W_{a}\right\|}\right)^{2}}{\left(\frac{1}{p}\right) \sum_{a=1}^{h} R^{2}\left(y, t_{a}\right)}}
$$

Where $W_{\text {aj }}$ denotes weight of the $j^{\text {th }}$ factor in component $a$ and $R^{2}\left(y, t_{a}\right)$ indicates fraction of variance in $\mathrm{y}$ explained by the component a.

Detailed methodology of PLS and VIP can be found in the study of Wold et al. (1993) and Akarachantachote et al. (2014).

\subsection{Generalized Additive Model (GAM):}

Very recently, GAM is extensively used in many studies and found useful to correlate COVID-19 cases with various local meteorological parameters (Ma et al 2020; Qi et al 2020; Prata et al 2020; Wu et al
2020). In the present study, log-linear GAM was applied to analyse the state specific associations between infected counts and regional climatic factors, topography and population density. Firstly, the basic model was built for total infected case as the outcome of all other input parameters. Then parameters were log-transformed as well as smooth spline function was incorporated particularly to $\mathrm{PD}$ and $\mathrm{E}$, because for only these two variables, standard deviation exceeded mean due to extremely high heterogeneity at regional level. Thus the equation become as:

$$
\begin{aligned}
\ln (\mathrm{NI})=\ln (\mathrm{T}) & +\ln (\mathrm{R})+\ln (\mathrm{SH})+\ln (\mathrm{WS}) \\
& +\ln (\mathrm{SR})+\ln (\mathrm{AET}) \\
& +\mathrm{s}(\ln (\mathrm{PD}))+\mathrm{s}(\ln (\mathrm{E}))
\end{aligned}
$$

This approach also helped to explore linear and nonlinear effects of various parameters to health outcomes in terms of COVID-19 infections.

\section{Results:}

\subsection{Descriptive analysis:}

Total 29,487 confirmed cases of infections are reported till April 27, 2020 across India. Maharashtra has registered the highest number of confirmed cases $(8,590)$, while only 9 among 36 provinces (comprising 28 states and 8 union territories in India), individually have registered more than 1000 such cases. Population density in India varies from 17 to 11,320 considering all the states and union territories (Table. 1). While considering different climatic variables, due to the broad latitudinal differences among states, a high variability in values is observed (Fig. 1). The annual mean temperature varies from $-5 \mathrm{fl} \mathrm{C}$ (Ladakh) to 28fl C (Puducherry) (Table 1), while highest annual mean rainfall is observed in Meghalaya (3,914 $\mathrm{mm})$ and the lowest in Ladakh $(164 \mathrm{~mm})$. Specific humidity ranges from $0.002 \mathrm{~kg} \mathrm{~kg}^{-1}$ to 0.015 $\mathrm{kg} \mathrm{kg}^{-1}$. Among all these states, range of actual evapotranspiration is observed to be very high (10.75-100.99 mm). Monthly mean wind speed above $10 \mathrm{~m}$ from the surface varies from $0.99 \mathrm{~m} \mathrm{~s}^{-1}$ to $2.76 \mathrm{~m} \mathrm{~s}^{-1}$. The solar radiation varies between $15,236 \mathrm{kj}$ $\mathrm{m}^{-2}$ day $^{-1}$ to $20,301 \mathrm{kj} \mathrm{m}^{-2}$ day $^{-1}$ 
(a)

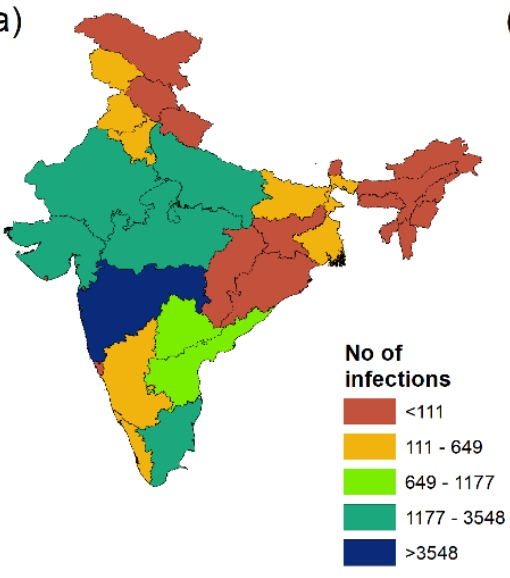

(b)

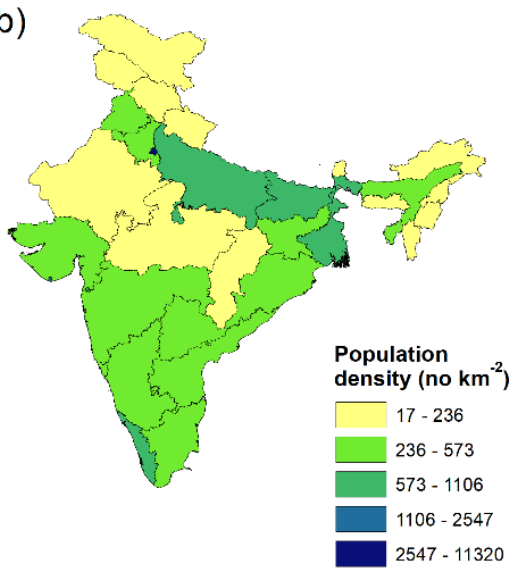

(c)

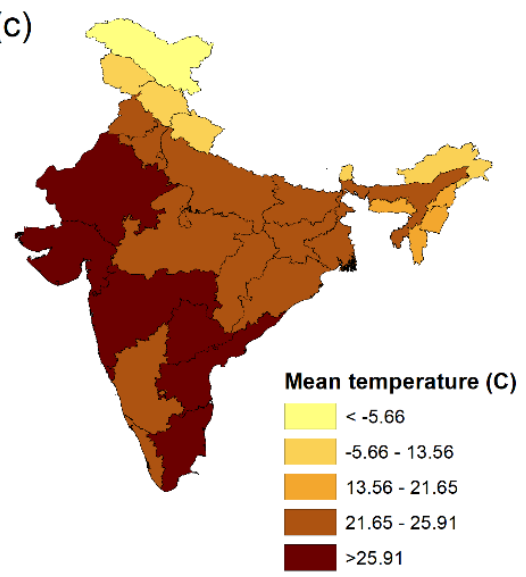

(d)

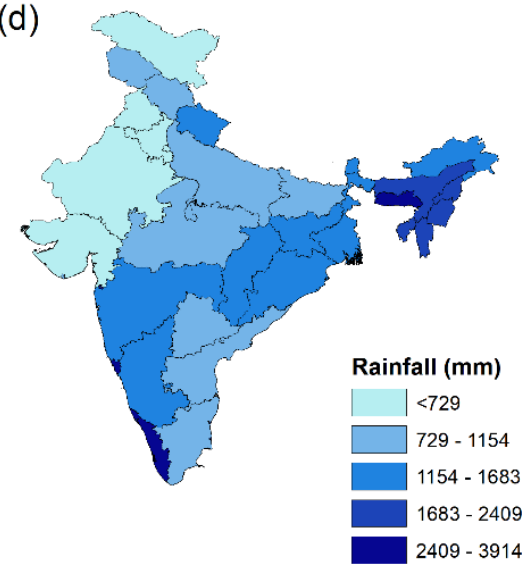

(e)

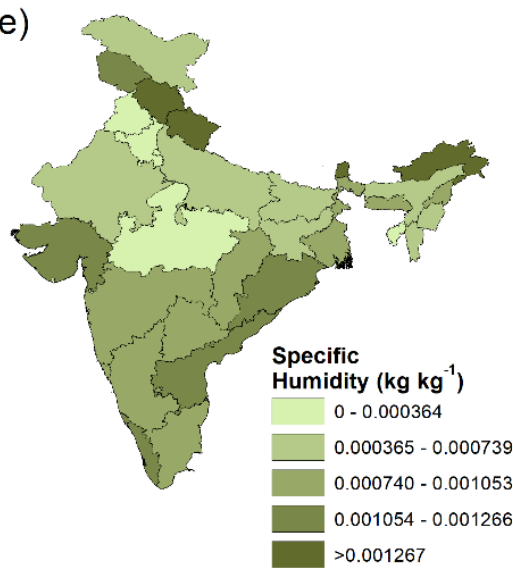

(f)

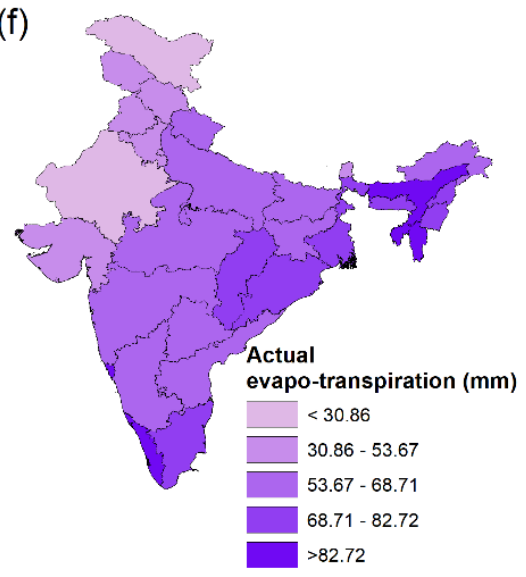

(g)

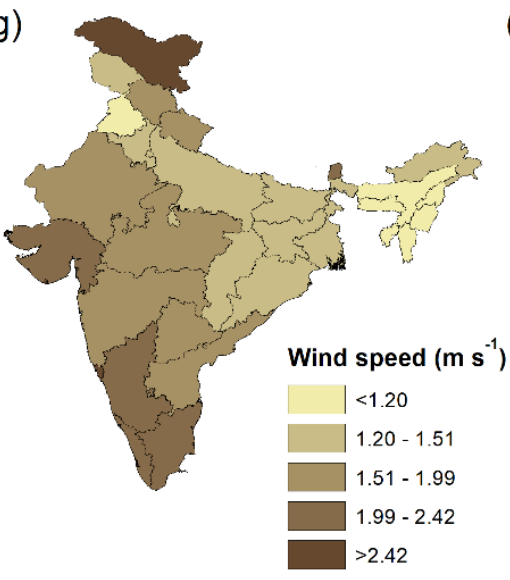

(h)

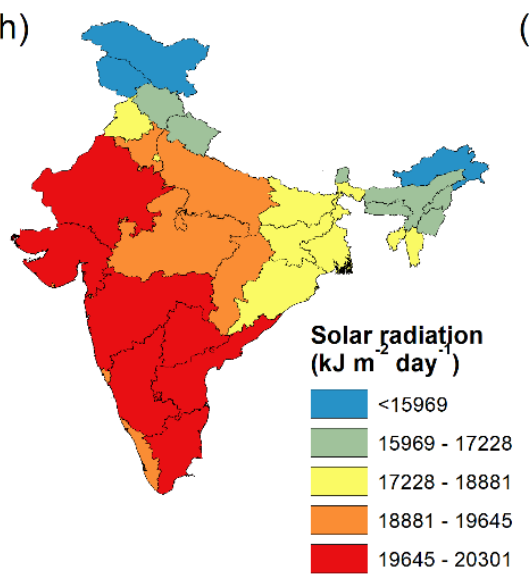

(i)

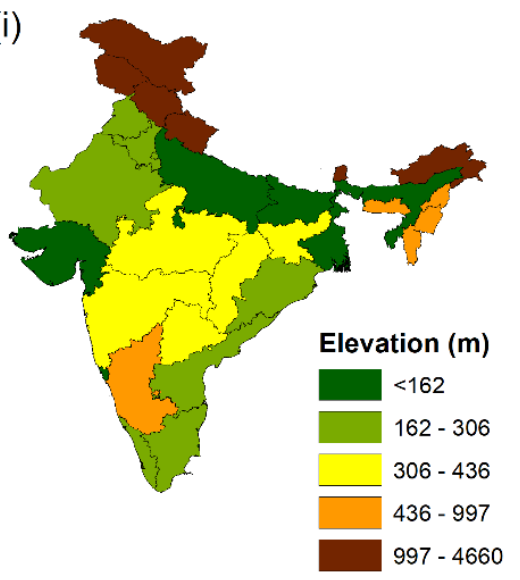

Fig. 1. The spatial distribution of different climate, topography, and social factors in India. (a) number of infections; (b) population density; (c) mean temperature; (d) rainfall; (e) specific humidity; (f) actual evapotranspiration; (g) wind speed; (h) solar radiation; and (i) elevation. 


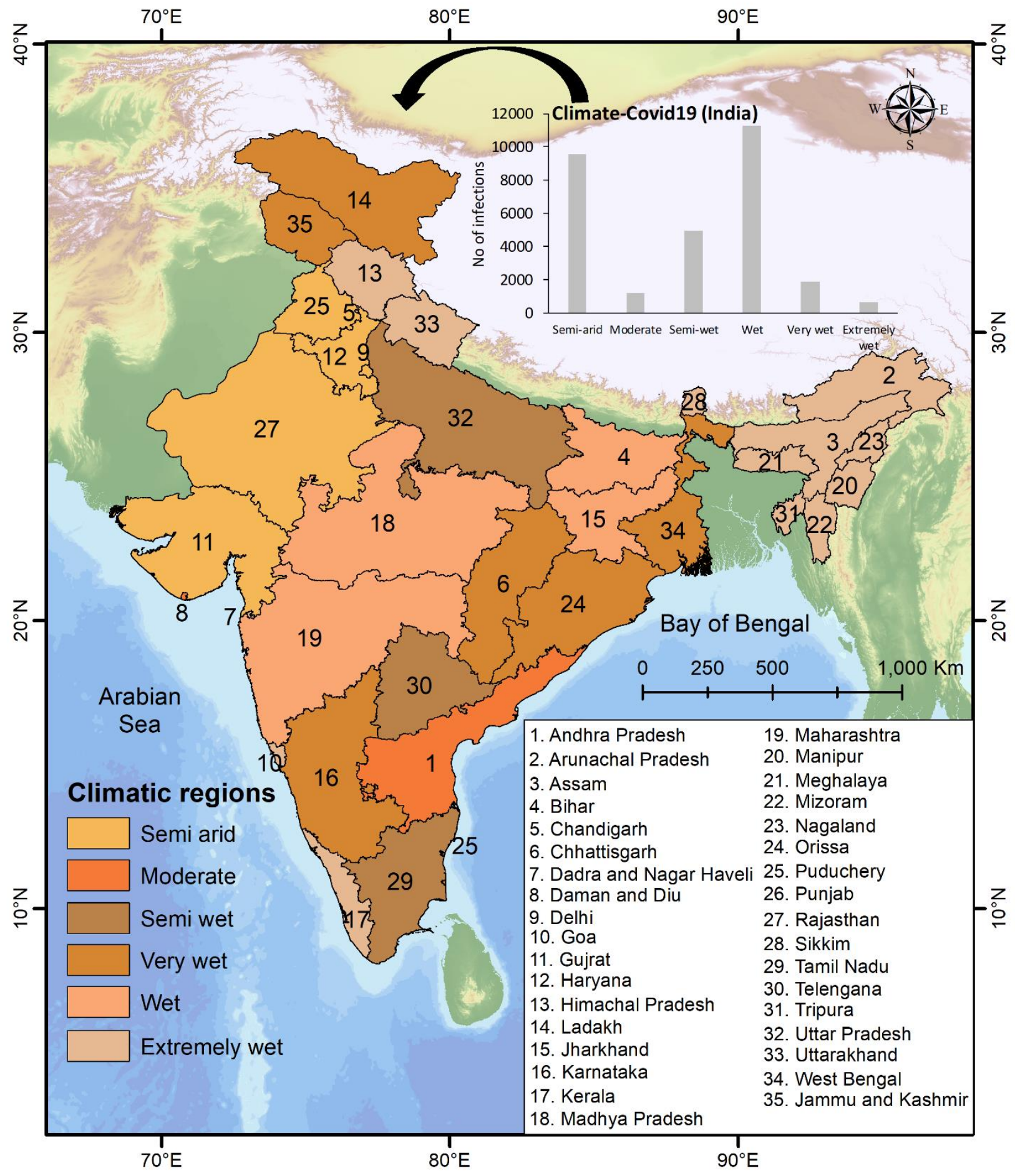

Fig. 2. De Martonne climatic classification of India. The inset bar-graph is indicating the total number of infections in each climatic zone. 
Table 1: Table is showing the descriptive statistics of state-wise Covid-19 infections and variation in climate in India

\begin{tabular}{|l|l|r|r|r|r|}
\hline Variable & Abbreviation & Minimum & Maximum & Mean & $\begin{array}{l}\text { Std. } \\
\text { deviation }\end{array}$ \\
\hline No of infections & NI & 1 & 8,590 & 948.96 & $1,727.96$ \\
\hline Population density & PD & 17 & 11,320 & $1,078.67$ & $2,518.87$ \\
\hline Temperature & T & -5.66 & 28.05 & 22.30 & 7.33 \\
\hline Rainfall & $\mathrm{R}$ & 164.06 & 3914.24 & $1,445.25$ & 855.01 \\
\hline Specific humidity & SH & 0.002 & 0.02 & 0.01 & 0.003 \\
\hline Actual evapotranspiration & AET & 10.74 & 100.98 & 65.18 & 19.05 \\
\hline Wind speed & WS & 0.99 & 2.75 & 1.66 & 0.49 \\
\hline Solar radiation & SR & $15,236.01$ & $20,301.36$ & $18,530.96$ & $1,436.27$ \\
\hline Elevation & E & 14.57 & $4,660.68$ & 717.39 & $1,037.25$ \\
\hline
\end{tabular}

Table 2: De Martone classification table of aridity index

\begin{tabular}{|l|l|}
\hline Classes & I value \\
\hline Hyper-arid & ¡5 \\
\hline Arid & $5-10$ \\
\hline Semi-arid & $10-20$ \\
\hline Moderate & $20-24$ \\
\hline Semi-wet & $24-28$ \\
\hline Wet & $28-35$ \\
\hline Very wet & $35-55$ \\
\hline Extremely wet & ¿55 \\
\hline
\end{tabular}

Table 3: Correlation among different variables (Bold with * indicates significant at $\alpha=0.05$ )

\begin{tabular}{|c|c|c|c|c|c|c|c|c|c|}
\hline Variables & $\mathrm{NI}$ & PD & $\mathrm{T}$ & $\mathrm{R}$ & SH & AET & WS & $S R$ & $\mathrm{E}$ \\
\hline $\mathrm{NI}$ & 1* & 0.112 & 0.269 & -0.285 & -0.014 & -0.265 & 0.178 & $0.415 *$ & -0.204 \\
\hline $\mathrm{P}$ & 0.112 & $1 *$ & 0.147 & -0.174 & -0.096 & -0.069 & -0.151 & 0.087 & -0.187 \\
\hline $\mathrm{T}$ & 0.269 & 0.147 & 1* & 0.179 & $0.771 *$ & $0.459 *$ & -0.108 & $0.829 *$ & $-0.983 *$ \\
\hline $\mathrm{R}$ & -0.285 & -0.174 & 0.179 & $1^{*}$ & $0.600^{*}$ & $0.808^{*}$ & -0.071 & -0.104 & -0.228 \\
\hline SH & -0.014 & -0.096 & $0.771 *$ & $0.600 *$ & $1^{*}$ & $0.808^{*}$ & 0.059 & $0.547 *$ & $-0.762 *$ \\
\hline AET & -0.265 & -0.069 & $0.459^{*}$ & $0.808^{*}$ & $0.808^{*}$ & $1^{*}$ & -0.135 & 0.119 & $-0.482 *$ \\
\hline WS & 0.178 & -0.151 & -0.108 & -0.071 & 0.059 & -0.135 & 1* & 0.330 & 0.226 \\
\hline SR & $0.415^{*}$ & 0.087 & $0.829 *$ & -0.104 & $0.547^{*}$ & 0.119 & 0.330 & $1^{*}$ & $-0.747 *$ \\
\hline $\mathrm{E}$ & -0.204 & -0.187 & $-0.983 *$ & -0.228 & $-0.762 *$ & $-0.482 *$ & 0.226 & $-0.747 *$ & $1 *$ \\
\hline
\end{tabular}


(a)

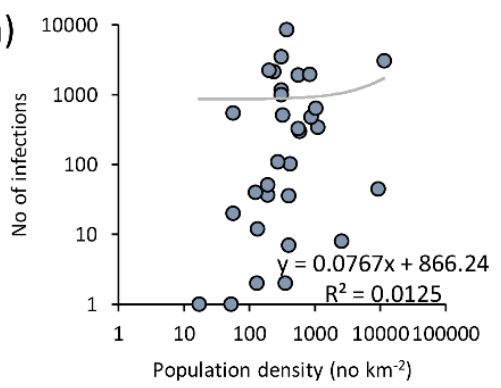

(d)

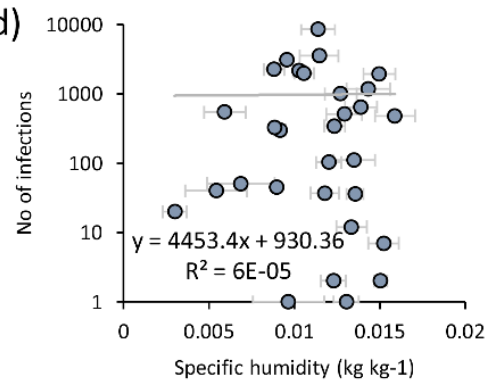

(g)

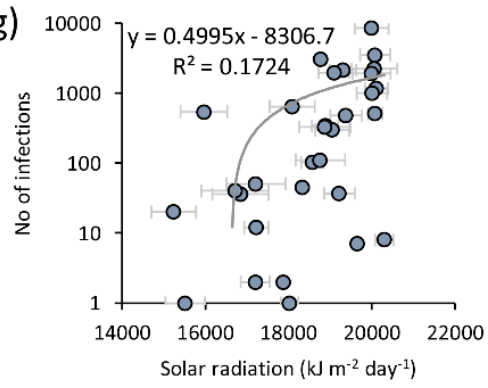

(b)

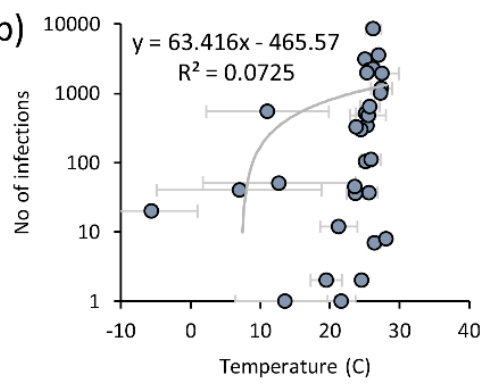

(e)

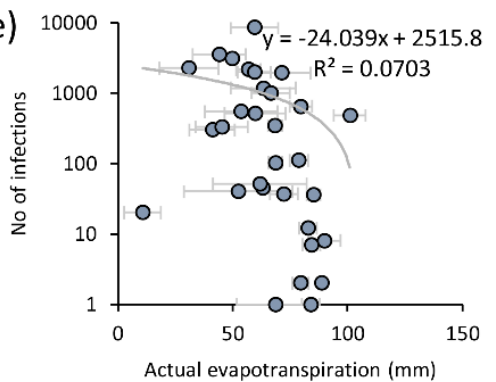

(h) $1000 \%=-0.3399 x+1192.8$

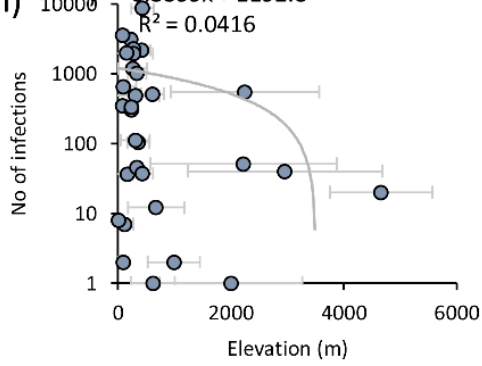

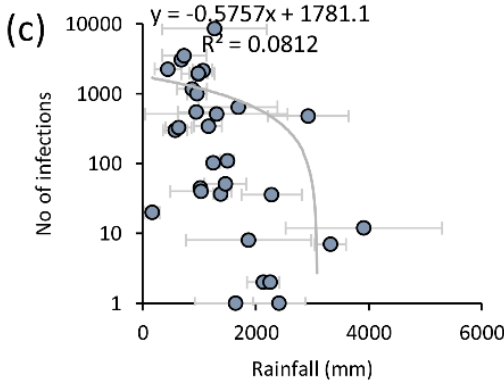
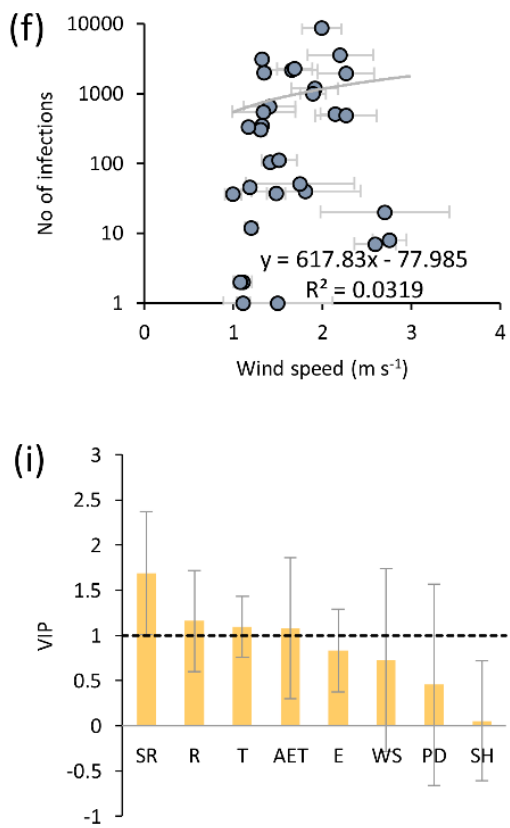

Fig. 3. Scatter plots and VIP values of individual variables with respect to the number of infections. (a) population density; (b) temperature; (c) rainfall; (d) specific humidity; (e) actual evapotranspiration; (f) wind speed; (g) solar radiation; (h) elevation and (i) VIP values.

\subsection{Climatic regions and Covid-19 cases:}

Based on De Martonne classification (Table 2 ), we found six different climatic zones in entire India (e.g. semi-arid, moderate, semiwet, wet, very wet and extremely wet) (Fig. 2 ). According to this climatic classification, we establish five provinces under semi-arid, two under moderate, three under semi-wet, five under wet, seven under very wet and thirteen under extremely wet categories. The spatial distribution of COVID-19 cases in India indicates, maximum transmissions occurred within the states that fall under semi-arid and wet categories. However, provinces under wet (7) and extremely wet
(13) categories are likely less infected by such transmission (Fig. 2).

\subsection{Bivariate correlation among variables:}

In order to understand the influence of different climatic and topographic factors, we performed bivariate correlation using the long-term climatic data and topographic elevation. Table 3 shows the Pearson correlation coefficients between each variable. We selected the number of infections as dependent variable and all the geographical parameters were correlated as independent variables. We observed a significant positive correlation between temperature and rainfall with specific 
humidity and actual evapotranspiration. A strong correlation between temperature with solar radiation $(+)$ and elevation (-) were also noticed (Table 3). Moreover, we found a significant positive relationship between the numbers of infections with solar radiation (Fig. 3). Although no such significant correlation were found between number of infections and other variables, a notable positive relationship with temperature and negative relationship with rainfall were observed. Similarly, specific humidity, actual evapotranspiration, and altitudinal variation has a negative relation with no of infections while wind speed shows a positive relation (Fig.. 3). Surprisingly, we found no significant correlation between population density with the number of infections. Mention worthy, improvement in correlation was noticed for most of the variables when the variables were log-transformed and inter-correlated.

\subsection{Variable importance of projection:}

Fig. 3i illustrates the variable importance of projection of each variable. A large value (i1) of VIP was recorded in case of solar radiation, rainfall, temperature and actual evapotranspiration. Elevation, winds speed, population density, and specific humidity were found having a VIP number lower than 1 .

\subsection{Implementing GAM:}

Using the GAM model, an attempt was made to relate the number of infected cases with all the geographical variables, which are taken into the consideration for this study. Initially, we found no significant relation $\left(\mathrm{R}^{2}=0.219\right)$ using simple linear GAM. However, log-transformed values of all variables significantly improved the performance of the model $\left(\mathrm{R}^{2}=0.782\right)$. Using the flexibility of spline smoothening function to log-transformed value of $\mathrm{PD}$ (Fig. 4a) and $\mathrm{E}$ (Fig. 4b), the $\mathrm{R}^{2}$ value mounted on 0.895 (Fig. 4c). The parametric coefficients and approximate significance of smooth terms are enlisted, which shows that all input parameters were able to fit in the model in such a way that all coefficients were found statistically significant at 0.05 significance level ( $\mathrm{p}$-valuesj0.05).

Log-transformed data with smoothening function to $\mathrm{E}$ and $\mathrm{PD}$ customized the model's prediction accuracy at a very significant level. Thus, it well explored the complex non-linearity in the relation of COVID-19 infections with the geographical distribution. Although, simple bivariate correlation doesn't produce any significant relevance, the sublime outcome through GAM model suggest multiple complex parameters to take into account for further investigation in any spatial context. GAM experiment depicts that NI is negatively associated with $\mathrm{SH}$ and $\mathrm{R}$, while positively associated with SR and T.
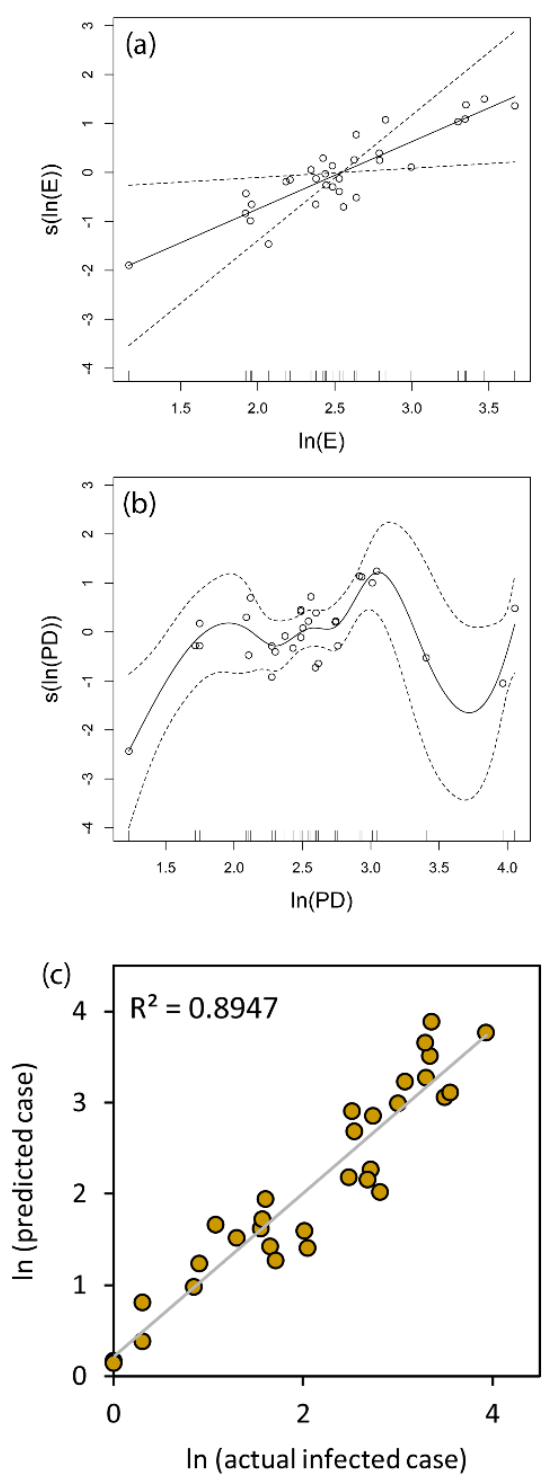

Fig. 4. Plots of GAM analysis.

(a) performance of GAM to related geographic factors; (b) residuals of smooth terms;

(c) relationship between the actual and predicted model. 


\section{Discussion:}

The recent COVID-19 has caused a significant health encumbrance in many places around the world (Ma et al. 2020). In this paper, we investigated the spatial relationship among long-term climate, topography and social factors with the counts of confirmed COVID-19 cases in India. A substantial amount of studies in different places around the world had already tried to examine if there were any correlations between COVID-19 outbreak and the existing weather or climatic conditions (Bashir et al. 2020; Sajadi et al. 2020). The prevailing meteorology (temperature, humidity, wind speed etc.) significantly alters the environmental stability, therefore, it might affect the sustainability of viruses and the transmission process (Tosepu et al. 2020). According to Chen et al. (2020), COVID-19 transmission is significantly affected by surrounding air temperature and humidity conditions, agreed by Shi et al. (2020), on the occasion of major outbreak in mainland of China.

In this study, we found a positive correlation between the number of infections with long-term climatic records of temperature, wind speed, solar radiation (significant) and population density. In China, Shi et al. (2020) reported a negative correlation between temperature and COVID-19 transmission on the basis of the daily weather report. However, Ma et al. (2020) reported a positive association with mortality rate and daily temperature in Wuhan, China. Subsequently, considering the global context, transmission is found higher in particular regions of subtropical countries where the surrounding air temperature is significantly low (Poole 2020).

The significant correlation between solar radiation and COVID-19 infection in India clearly indicates that high insolation during daytime does not prevent COVID-19 transmission. However, sunlight has the ability to boost the immune system and slow down the growth of infections in human body (Cannel et al. 2006; Miller
2018; Asyary and Veruswati 2020). Asyary and Veruswati (2020) investigated the role of sunlight in Covid-19 outbreak and recovery. These workers didn't observe any noticeable trend of sunlight exposure with the transmission rate, but, reported a significant recovery rate under sunlight exposure.

Our study indicates a negative association between rainfall, specific humidity, actual evapotranspiration and elevation. A timeseries study from China indicated a negative correlation between daily relative humidity and COVID-19 transmission (Qi et al. 2020). Moreover, a large number of previous epidemiological investigations reported a negative association between humidity and corona virus alike diseases (Zhang Qiang et al. 2004; Gardner et al. 2019). Thus, agreed the findings of present research on Indian context.

Until now, unwanted limelight was noticed about the relation between regional topography and COVID-19 transmission. We subsumed the average elevation for each province, since, it significantly controls the climatic conditions. Our study indicated, the regions in low lying elevation in India are more likely to get infected by higher Covid-19 transmission.

Occurrence of infection counts in various climatic regions suggests that the transmission rate is likely inferior in the provinces under very wet and extremely wet categories of climatic conditions, thus, significantly stipulate lower rate of transmission in wet condition. Moreover, accounting $29.2 \%$ of total cases in India, Maharashtra has been already opened up as the prime hotspot. Moreover, $24.72 \%$ of the total cases were found in neighbouring states (i.e. Gujrat, Madhya Pradesh, Goa, Chhattisgarh and Telengana). This might be a result of rapid migration before lockdown (March 25, 2020).

In the present study, we found significant outcome of predicting infected cases through GAM model accounting several geographical parameters altogether. From GAM model, we understood that hot and dry areas are more likely to be infected by 
COVID-19 transmission. Higher WS at micro scale may induce the ventilation, but, our study suggests, it will not have suitable impact over regional scale. Residual plots of smooth terms (i.e., PD and E) indicate that population statistics or regional topography may not have any accountability solely, however, these are important with a combination with meteorology.

Same as any scientific investigations, our study has a significant amount of limitations: (i) we have presented only longterm climatic records to indicate the association between COVID-19 cases and prevailing circumstances. There is indeed a requirement of investigation using real time daily weather data in different states. (ii) As the disease is caused by a virus, there are lots of other factors that might be considered such as population migration, immunity power, age groups, hygiene systems etc. Despite of having limitations, this study is highly significant as it is the first report that is investigating the association of climate and COVID-19 transmission in Indian context. This is simply a basic analysis and a large amount of data (district wise) might be incorporated for a stronger conclusion.

\section{Conclusion:}

The present study signifies the geographical influence on COVID-19 transmission at regional level in the context of India. It is well emphasized by several statistical analyses that climatic records have unavoidable influence on this viral disease. The heterogeneity in the spatial occurrence of infections might be attributed to local meteorology with its geographical location and population. However, no single attribute individually can well explain the nature of transmission. Positive association with solar radiation and temperature as well as negative association with humidity and rainfall suggest that hot and arid areas in low altitude regions are required to strictly follow up preventive measures in an emergency basis.

\section{Author's Contribution:}

Amitesh Gupta: Conceptualization, Methodology, Software, Validation, Writing original draft; Sreejita Banerjee: Data collection, Writing: review and editing; Sumit Das: Conceptualization, Methodology, Software, Visualization, Writing original draft

\section{Acknowledgement:}

S.D. and S.B. wish to thank the Department of Geography, Savitribai Phule Pune University, for providing necessary facilities to carry out this study. All authors are thankful to covid19india.org, census India, CGIAR, TerraClimate and Worldclim websites for providing required data used in this study.

\section{References:}

Ahmadi, M., Sharifi, A., Dorosti, S., et al., 2020. Investigation of effective climatology parameters on COVID-19 outbreak in Iran, Science of the Total Environment, https://doi.org/10.1016/j.scitotenv.2020.138705

Akarachantachote, N., Chadcham, S., Saithanu, K., 2014. Cutoff threshold of variable importance in projection for variable selection. International Journal of Pure and Applied Mathematics 94, 307322

Asyary, A., Veruswati, M., 2020. Sunlight exposure increased Covid-19 recovery rates: A study in the central pandemic area of Indonesia.

https://doi.org/10.1016/j.scitotenv.2020.139016

Baltas, E., 2007. Spatial distribution of climatic indices in northern Greece. Meteorological Applications 14, 69-78

Bashir, M.F., Ma, B., Bilal., Komal, B., Bashir, M.A., Tan, D., Bashir, M., 2020. Correlation between climate indicators and COVID-19 pandemic in New York, USA. Science of the Total Environment 728, 138835

Cannell, J.J., Vieth, R., Umhau, J.C., Holick, M.F., Grant, W.B., Madronich, S., Garland, C.F., 
Giovannucci, E., 2006. Epidemic influenza and vitamin D. Epidemiol. Infect. 134, 1129-1140.

Casanova, L.M., Jeon, S., Rutala, W.A., Weber, D.J., Sobsey, M.D., 2010. Effects of air temperature and relative humidity on coronavirus survival on surfaces. Appl. Environ.

Microbiol. 76, 2712-271

Chen B, Liang H, Yuan X, Hu Y, Xu M, Zhao Y, et al. Roles of meteorological conditions in COVID-19 transmission on a worldwide scale. medRxiv 2020.

Dalziel, B.D., Kissler, S., Gog, J.R., Vibourd, C., Bjornstad, O.N., Metcaff, J.E., et al., 2018. Urbanization and humidity shape the intensity of influenza epidemics in U.S cities. Science 362, 75-79.

De Martonne E. 1925. Traitj e de Gj eographie Physique: 3 tomes, Paris.

Gardner, E.G., Kelton, D., Poljak, Z., Van

Kerkhove, M., von Dobschuetz, S., Greer, A.L., 2019.

A case-crossover analysis of the impact of weather on primary cases of Middle East respiratory syndrome. BMC Infect. Dis. 19, 113.

Gorbalenya, A.E., 2020. Severe acute respiratory syndrome-related coronavirus-the species and its viruses, a statement of the Coronavirus Study Group. BioRxiv, 1-15 https://doi.org/10.1101/2020.02.07.937862.

Holshue, M.L., DeBolt, C., Lindquist, S., Lofy, K.H., Wiesman, J., Bruce, H., et al., 2020. First case of 2019 novel coronavirus in the United States. N. Engl. J. Med.

Li, Q., Guan, X., Wu, P., Wang, X., Zhou, L., Tong, Y., et al., 2020. Early transmission dynamics in Wuhan, China, of novel coronavirus-infected pneumonia. N. Engl. J. Med.

Li, Y., Huang, X., Yu,I.T., et al., 2005. Role of air distribution in SARS transmission during the largest nosocomial outbreak in Hong Kong. Indoor Air 15, 83-95.

Ma, Y., Zhao., Y., Liu, J., He, X., Wang, B., Fu, S., Yan, J., Niu, J., Zhou, J., Luo, B., Effects of temperature variation and humidity on the death of COVID-19 in Wuhan, China. Science of the Total Environment 724, 138226

Miller, B., 2018. Immune System: Your best defense against viruses and bacteria from the common cold to the SARS virus. Oak Publication Sdn Bhd.

Prata, D.N., Rodrigues, W., Bermejo, P.H., 2020. Temperature significantly changes COVID-19 transmission in (sub) tropical cities of Brazil. Science of the Total Environment

Perlman, S., 2020. Another decade, another coronavirus. Mass Medical Soc.

Poole, L., 2020. Seasonal Influences on the Spread of SARS-CoV-2 (COVID19), Causality, and Forecastabililty (3-15-2020). Causality, and Forecastabililty (3-15-2020). (March 15, 2020).

Qi, H., Xiao, S., Shi, R., Ward, M.P., Chen, Y., Su, Q., Wang, W., Wang, X., Zhang, Z., 2020. COVID19 transmission in mainland chaina is associated with temperature and humidity: a time-series analysis. Science of the Total Environment 728, 138778

Sajadi, M.M., Habibzadeh, P., Vintzileos, A., Shokouhi, S., Miralles-Wilhelm, F., Amoroso, A., 2020. Temperature and Latitude Analysis to Predict Potential Spread and Seasonality for COVID-19. Available at SSRN 3550308.

Shi, P., Dong, Y., Yan, H., Zhao, C., Li, X., Liu, W., He, M., Tang, S., Zi,S., 2020. Impact of temperature on the dynamics of the COVID-19 outbreak in China. Science of the Total Environment 728, 138890.

Singhal, T., 2020. A Review of Coronavirus Disease2019 (COVID-19). Indian J. Pediatr. 87, 281-286. https://doi.org/10.1007/s12098-020-03263-6

Wold S, Johansson A, Cochi M (eds).PLS-partial least squares projec-tions to latent structures. ESCOM Science Publishers: Leiden, 1993;523-550.

Wu, F., Zhao, S., Yu, B., Chen, Y., Wang, W., Song, Z., Hu, Y., Tao, Z., Tian, J., Pei, Y., Yuan, M., Zhang, Y., Dai, F., Liu, Y., Wang, Q., Zheng, J., Xu, L., Holmes, E.C., Zhang, Y., 2020. A new coronavirus associated with human respiratory disease in China. Nature 579 (7798), 265-269. https://doi.org/10.1038/s41586-020-2008-3

Xu, Z., Shi, L., Wang, Y., Zhang, J., Huang, L., Zhang, C., Liu, S., Zhao, P., Liu, H., Zhu, L., others, 2020. Pathological findings of COVID-19 associated with acute respiratory distress syndrome. Lancet Respir. Med.

Zareiee, A.R., 2014. Evaluation of changes in different climates of Iran, using De Martonne index and Mann-Kendall trend test. Nat. Hazards Earth Syst. Sci. Discuss. 2, 2245-2261.

Zhang Qiang, Y.X.-W., Ye, Dian-xiu, Xiao, Fengjin, Cheng, Zheng-hong, 2004. Meteorological characteristics and their impacts during the SARS epidemic period. J. Nanjing Institute Meteorol. 849855 